\section{Costochondral Deformity Masquerading as a Submucosal Gastric Tumor}

A 55-year-old woman was referred for endoscopic ultrasound (EUS) to evaluate a "submucosal gastric tumor" which had been detected on esophagogastroduodenoscopy. This had been performed to investigate symptoms of dyspepsia. Repeat EGD revealed an area of compression of the proximal anterior gastric wall which seemed to be of an extrinsic nature. This was only apparent during maximal air insufflation (Figure 1) and disappeared when the stomach was partially deflated. A respiration-dependent movement of the "tumor" along the gastric wall was noted and probing with a biopsy forceps revealed it to have a hard consistency. EUS demonstrated that the gastric wall layers were intact and the presence of an extrinsic hypoechoic lesion (Figure 2 ). The outer margin of the lesion was not well visualized and its origin could not be clarified on EUS. Computed tomography and conventional radiographs revealed a deformity of the anterior end and costochondral junction of the left sixth rib, which was displaced posteriorly and intended the anterior gastric wall (Figure 3 ). On further questioning, the patient told us that she had been a passenger in a car accident several years before. She said that

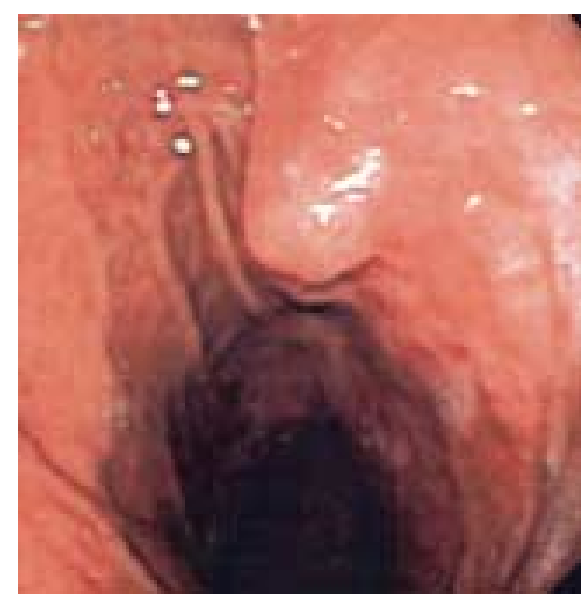

Figure 1 Endoscopic view of the "submucosal" gastric lesion after maximal air insufflation. she had had a "bruised left side for many weeks" but had not sought medical attention. Even with the benefit of hindsight, the rib deformity was not palpable on examination.

Endoscopic ultrasound is a useful tool in the evaluation of patients with submucosal gastric tumors or extraluminal compression [1 - 3]. In our patient, respiratory movement of the lesion relative to the stomach suggested that it was either related to the rib cage or to the diaphragm. Another patient who presented with a "submucosal gastric tumor", described recently, was found to have a mesothelioma extending through the diaphragm [4]. As shown in our case, deformities of the lower ribs and costochondral junction may also create the impression of a submucosal gastric tumor and should be considered in the differential diagnosis when an indentation of the proximal gastric wall is noted on endoscopy.

\section{K. Mergener, J. J. Brandabur}

Section of Gastroenterology,

Virginia Mason Medical Center,

Seattle, Washington, USA

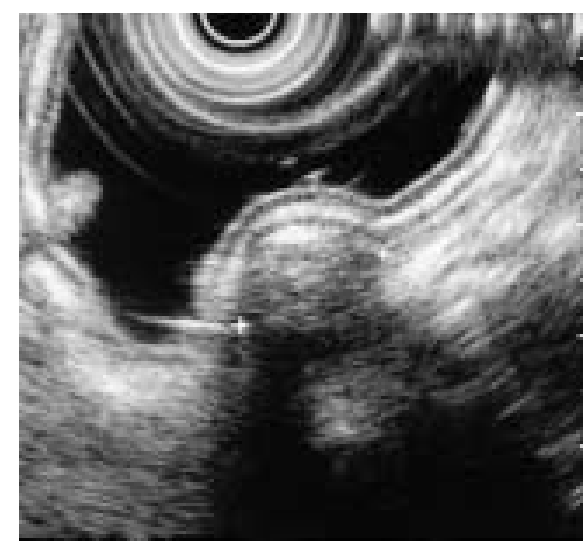

Figure 2 Endoscopic ultrasound showing intact gastric wall layers and a hypoechoic mass extrinsic to the stomach.

\section{References}

${ }^{1}$ Rösch T, Lorenz R, Dancygier H et al. Endosonographic diagnosis of submucosal upper gastrointestinal tumors. Scand J Gastroenterol 1992; 27: 1 -8

${ }^{2}$ Rösch T. Endoscopic ultrasonography in upper gastrointestinal submucosal tumors: a literature review. Gastrointest Endosc Clin N Am 1995; 5: 609-615

${ }^{3}$ Zhang QL. Endoscopic ultrasonography diagnosis in submucosal tumor of stomach. Endoscopy 1998; 30: A69A71

${ }^{4}$ Gerke H, Bittinger F, Galle PR, Mergener K. Diagnosis of a pleural mesothelioma by endosonography-guided transgastric fine-needle aspiration. Endoscopy 2000; 32: 906

\section{Corresponding Author}

\section{K. Mergener, M.D.}

Gastroenterology Section

Virginia Mason Medical Center

1100 Ninth Avenue

Seattle, WA 98101, USA

Fax: + 1-206-223-6379

E-mail: klaus.mergener@vmmc.org

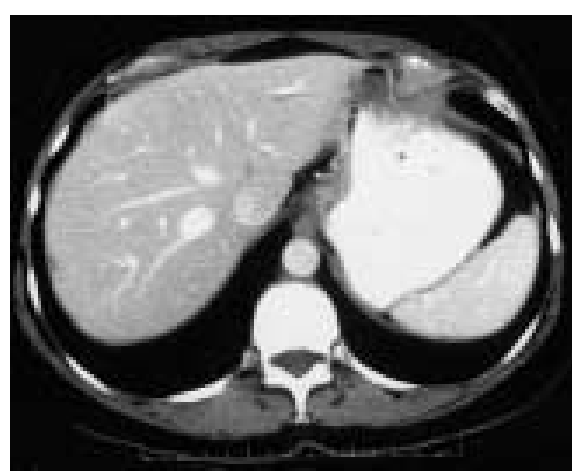

Figure 3 Computed tomography demonstrating the deformity and posterior displacement of the left sixth rib, which have resulted in indentation of the upper stomach. 